\title{
La Regenta y los feminismos
}

\author{
La Regenta and feminisms
}

\begin{abstract}
Isabel Navas Ocaña
Universidad de Almería, Depto. de Filología, La Cañada de San Urbano s/n 04120, Almería, España, e-mail:minavas@ual.es
\end{abstract}

\begin{abstract}
El principal objetivo de este trabajo es el estudio de las lecturas que desde una perspectiva feminista se han hecho de La Regenta de Clarín. La aportación de la crítica feminista a esta parcela de la literatura española ha sido muy grande, con sugestivos análisis de los personajes femeninos de la novela, de la misoginia presente en ellos, etc. El feminismo, o mejor, los feminismos, se han servido para aproximarse a La Regenta desde teorías muy diversas, desde la sociología literaria al materialismo cultural, pasando por el psicoanálisis, la semiótica o la deconstrucción. Dilucidar qué conclusiones o qué interpretaciones se han hecho de La Regenta desde estas modalidades críticas, desde estos feminismos, será la tarea fundamental que nos ocupe en las páginas que siguen.
\end{abstract}

Palabras clave: feminismos, teoría de la literatura, crítica literaria, literatura española, siglo XIX.

The main objective of this work is to study the readings from a feminist perspective has been made of La Regenta's Clarín. The contribution of the feminist critique to this topic of Spanish literature has been very large, with suggestive analysis of the female characters in the novel, misogyny present in them, and so on. Feminism, or better, feminisms, have served to approach La Regenta from wide range of theories, from the sociology of literature to cultural materialism, through psychoanalysis, semiotics and deconstruction. To draw what conclusions or interpretations which have been made of La Regenta from these modalities of criticism, since these feminisms, will be the primary task that we deal with in this paper.

Key words: feminism, theory of literature, literary criticism, Spanish literature, century XIX.

\section{El ADUlterio y LA IDEOLOGÍA DE LA DOMESTICIDAD}

Las primeras lecturas en clave feminista de la obra de Clarín, y en concreto de $L a$ Regenta, el texto más comentado, apuntan hacia explicaciones de carácter sociohistórico de la problemática del adulterio. Biruté Ciplijauskaité lo considera el primer síntoma de la ruptura del contrato matrimonial y de la desintegración de la familia. Por esa razón, "la mayor parte de las novelas "burguesas" del siglo XIX se desenvuelven alrededor del tema de la familia imperfecta como contraste a la novela anterior" $(1984: 43)^{1}$

\footnotetext{
${ }^{1}$ Ciplijauskaité hace un análisis comparativo de Ana Karenina de Tolstoi, Madame Bovary de Flaubert, La Regenta de Clarín y Effi Briest de Fontane. En un trabajo posterior (2002), estudia la continuidad del tema del adulterio desde La Regenta a la novela contemporánea. Las semejanzas de Ana Ozores con Effi Briest también
} 
Lou Charnon-Deutsch (1990) también observa en Clarín y en Galdós una intensa preocupación por la crisis de las dos instituciones burguesas básicas: el matrimonio y la familia. Para hacer frente a esta crisis, ambos defienden la educación de la mujer. Participan de la idea krausista de que una mujer educada puede cumplir mejor su papel dentro de la institución familiar, sobre todo en lo que se refiere a la educación de los hijos. Contribuyen así a reforzar la "ideología de la domesticidad", el modelo femenino del "ángel del hogar" (Aldaraca 1992), que no es en realidad sino una estrategia de contención de las nacientes aspiraciones feministas.

De ahí que en estos primigenios atisbos de crisis de la institución familiar Ciplijauskaité observe un hecho fundamental: las mujeres se van a rebelar no tanto contra el marido sino contra la sociedad. El punto de partida de Ana Karenina, Madame Bovary y Ana Ozores es "su deseo de evasión del aburrimiento, de la monotonía de la rutina diaria, de una existencia enjaulada sometida a reglas precisas" (1984: 48). De hecho, Lisa Gerrard culpa a la misógina sociedad del XIX de la opresión de la mujer y de su destrucción. La Regenta es, en su opinión, "a devasting picture of the devaluation and oppression of women", de la "disintegration of an intelligent, sensitive woman in a misogynistic society" (1987: 91 y 95).

\section{LOS CONFLICTOS FEMENINOS COMO SÍMBOLO DEL ENFRENTAMIENTO DEL ARTISTA DECIMONÓNICO CON LA SOCIEDAD}

Pero Gerrard va más allá y plantea incluso la identificación de Clarín con el personaje de Ana Ozores, "his intuitive sympathy for a female character oppressed by sexist attitudes and institutions" (id.: 91). Según Gerrard, la opresiva vida provinciana que padece la Regenta la vivió también Clarín. Como Ana, Clarín es un artista al que la corrupción de la vida política e intelectual llega a desalentarle tanto que se plantea incluso el hecho de dejar de escribir. Por eso, concluye que "In a novel concerned with the struggle between artist and society, Alas has rendered the artist's dilemma as a woman's persecution by sexist attitudes. Hence, the sympathetic rendering of her opression and the feminism that colors the confrontation between artist and society" (Ibíd: 96). En definitiva, no se trata sólo de demostrar la simpatía de Clarín hacia una mujer cuyas iniciativas son sistemáticamente frustradas por una sociedad misógina que condena su sexualidad y su inteligencia, ni se trata sólo de ver en Ana Ozores el alter ego de Clarín ${ }^{2}$, sino de convertir los conflictos femeninos en símbolo del enfrentamiento del artista con la sociedad, aspecto éste de gran trascendencia en la literatura decimonónica desde el romanticismo a las teorías del arte por el arte (Navas Ocaña 2007: 234-260).

han interesado a Anna Rossell (1997), mientras que Socorro Suárez-Lafuente (1988) ha señalado coincidencias muy llamativas entre Ana Ozores y la Edna Pontellier de The Awakening (1899), de Kate Chopin.

2 Sobre el "ángel del hogar" es ya un clásico el trabajo de Bridget Aldaraca El ángel del hogar. Galdós y la ideología de la domesticidad en España (1992). 


\section{3. "Clarín”, ¿FEMINISTA O MisóGino?}

Ahora bien, para sostener esta tesis Gerrard se ve en la obligación de hacer frente al antifeminismo de Clarín, mostrado públicamente en textos como "Psicología del sexo" (1894), donde da argumentos biológicos para justificar los papeles tradicionales atribuidos a cada $\operatorname{sexo}^{3}$, y en novelas como Su único hijo (1890) y Teresa $(1895)^{4}$, o en la polémica relación que mantuvo con Emilia Pardo Bazán. Gerrard habla de un proceso evolutivo que conduce a Clarín desde el liberalismo y el krausismo de juventud al conservadurismo de su madurez. En ese proceso Clarín oscila entre una inicial simpatía hacia la educación femenina, idea de origen krausista que inspira según Gerrard el feminismo de La Regenta, y posiciones más tradicionales presentes en Su único hijo y en Teresa. Pero no se debe olvidar que las teorías krausistas sobre la educación femenina vinieron a reforzar la reclusión de la mujer en el ámbito de la domesticidad y que, por esa razón, no están tan lejos como a primera vista podría pensarse del determinismo biológico con el que Clarín define las diferencias entre los sexos.

Además, otras críticas feministas, como Sara E. Schifter (1982) y Elena Gascón Vera (1992), han visto también ese determinismo en la caracterización del personaje de Ana Ozores: la maternidad frustrada es la principal razón aducida a lo largo de la novela para justificar, pero no perdonar, el adulterio ${ }^{5}$. Schifter observa el mismo planteamiento determinista en la insistente presentación de Ana como una mujer al

\footnotetext{
3 Asunto también apuntado por Ciplijauskaité: "La frustración de todos los personajes es un reflejo de la frustración personal de Clarín. De aquí su mordacidad" (1984: 51).

${ }^{4}$ Según Clarín, la objetividad, la innovación y el altruismo son rasgos que genera en exclusiva la actividad del órgano masculino y, en consecuencia, tareas como la política, las artes o las ciencias sólo serán posibles al hombre, mientras que la mujer ha de replegarse a la vida familiar, a la conservación de las tradiciones y del hogar. Gerrard no los menciona pero hay otros textos en donde se aprecian igualmente los prejuicios de Clarín contra las mujeres. El titulado "Las literatas" es uno de ellos. Aquí pueden leerse declaraciones tan sabrosas como "La mayor parte de las literatas son feas", ya que "la mujer fea suele recurrir a las recónditas perfecciones de su espíritu para llamar el interés de los hombres" (1989: 232). Clarín además se escandaliza de que las escritoras relaten en sus obras historias de amor: "Para comprender todo el horror de semejante aberración, ponte en el caso del amante que encuentra en una novela de la mujer querida la escena del primer sí, o tal vez del primer beso. Si el amante es verdadero se creerá tantas veces... engañado, cuantos ejemplares de la obra se hayan vendido" (Ibid.: 233). Y en lo que se refiere a la entrada de Emilia Pardo Bazán en la Academia, Clarín es muy tajante: “(...) las señoras no deben ser académicas” (Ibid.: 242), porque ni de lejos igualan en méritos a los hombres: “(...) no cabe duda de que hay mujeres de mucho talento; pero sin ofender a nadie, no cabe duda que, en general, comparadas con los hombres se quedan tamañitas. Lo que son ellas más guapas. Y no todas; ;porque hay cada coco! Pero para listos, nosotros" (Ibid. 243). Estoy citando por el volumen Clarín, político, preparado por Yvan Lissorgues (1989). Luis Saavedra (1987) ha analizado las críticas de Clarín a Pardo Bazán, desde el prólogo que escribió en 1883 para La cuestión palpitante, en donde se mostraba muy condescendiente con la escritora gallega y le reconocía además a las mujeres el derecho a la escritura, hasta el folleto titulado "Museum" (1890), que evidencia un drástico cambio de opinión, con reflexiones de acusado tono misógino sobre aquellas escritoras "varoniles" que, como la Pardo Bazán, se han lanzado a la literatura olvidándose de su condición femenina.
}

5 Abigail Lee Six (1999) y Ricardo Rodrigo Mancho (2002) han señalado la misoginia en la representación de los personajes femeninos de Su único hijo. El arquetipo misógino de Medusa está presente en el personaje de Emma y en el de Serafina (Six, 1999: 201-203). Ambas exhiben una mirada tan fiera, tan temible como la de Medusa. En cuanto a Emma, contradice el ideal de la perfecta casada de Fray Luis (Rodrigo Mancho, 2002: 239) y sobre todo la imagen tradicional de la maternidad, convirtiéndose en una "Madre Terrible" (Valis, 1981: 138 (Six, 1999: 209). Su miedo al parto, su temor al deterioro físico del embarazo y el deseo de abortar expresado de manera explícita así lo evidencian. Además, Clarín no duda en feminizar, en presentar como afeminados, a los personajes masculinos de carácter débil como Bonifacio. Así lo han indicado Noël Valis (1981: 16) y Abigail Lee Six (1999: 199-201). 
borde de la locura. Y arremete directamente contra Clarín por expresar los conflictos sociales femeninos en términos de enfermedad mental: "Such women are punished by society and by the authors who describe them as being on the verge of insanity whenever they confront their multiple conflicts" (1982: 233).

\section{4. “CLARÍN” Y EL FEMINISMO HUMANISTA Y LIBERAL}

El feminismo en su versión humanista y liberal, del que hacen gala aquí tanto Ciplijauskaité como Schifter y Gerrard, es un feminismo emparentado con las tesis realistas de Lukàcs, con la exigencia de que la obra literaria refleje una experiencia humana de carácter representativo en su contexto social ${ }^{6}$. No ha de sorprendernos, por tanto, que junto a causas sociológicas o históricas estas críticas feministas recurran con frecuencia a aspectos biográficos y que interpreten siempre en términos colectivos la experiencia individual, tanto la del personaje como la de su autor. Por eso, $L a$ Regenta se convierte en la expresión literaria de la crisis de la institución familiar, de la opresión de la mujer en una sociedad misógina y del enfrentamiento entre el artista y la sociedad. Y todo ello apoyado en argumentos biográficos: la influencia de las ideas krausistas en Clarín, sus tensas relaciones con la vida intelectual y política de la época, su frustración, su conservadurismo de madurez, etc. Pero lo curioso, y lo verdaderamente interesante, es que, en pos de la teoría del reflejo, de una teoría que apuesta por el realismo, por el verismo de la representación, la actitud de Clarín en La Regenta llegue a ser enjuiciada de forma totalmente diferente, contradictoria incluso. Mientras Lisa Gerrard defiende el feminismo de la novela y lo justifica con un dato que se pretende objetivo (el liberalismo del joven Clarín), Sara Schifter niega ese feminismo con una estrategia similar (la presencia de las teorías clarinianas sobre el determinismo biológico en la representación de Ana Ozores). Un mismo planteamiento realista produce por tanto conclusiones bien distintas. Este tipo de crítica que en ningún caso se cuestiona la existencia de una única verdad en el texto, de la que el autor es el garante último ${ }^{7}$, no duda tampoco en ofrecer su lectura de ese texto como si se tratase de la única y verdadera lectura posible. Confrontar, sin embargo, estas verdades absolutas no nos conduce sino a la convicción de su relativismo.

\subsection{ANA OZORES Y EL SEXO}

No faltan por supuesto estudios que aborden la problemática de la locura y del biologismo desde una perspectiva psiquiátrica o psicológica. De hecho, Bridget A. Aldaraca (1990) y Jo Labanyi (1991) han examinado la histeria en el personaje de Ana Ozores como manifestación patológica de un matrimonio carente de sexualidad. Pero, antes de entrar de lleno en estas lecturas, voy a comentar algunos aspectos

\footnotetext{
6 Según Schifter, "The novelist's view of the female's need for maternity as both a biological and psychological imperative echoes the traditional patriarchal judgment on female destiny" (1982: 237). Y Gascón Vera afirma: "Asimismo, en relación con Ana Ozores y su falta de hijos, el autor parece indicar que la maternidad podría haber sido su salvación y que es la ausencia del hijo lo que le lleva a aburrirse y verse tentada por el adulterio" (1992: 166).

7 Toril Moi demostró estas relaciones en un ensayo emblemático: “QQuién teme a Virginia Woolf? Lecturas feministas de Woolf (1987). Y, por eso, se le pueden pedir cuentas, como hace Schifter, se le puede acusar de una conducta reprobable.
} 
interesantes planteados por la crítica feminista de raigambre realista, humanista y liberal en torno a la sexualidad femenina. Tanto Sara Schifter como Lisa Gerrard denuncian el tratamiento negativo dado en La Regenta a la sexualidad femenina. Por ejemplo, la aventura con Germán en la barca tiene consecuencias dramáticas para Ana ya que se interpreta como un escándalo. Según Schifter, desde entonces Ana asocia la sexualidad con un intenso sentimiento de culpabilidad, de temor y con una cierta repugnancia (1982: 232). Para Gerrard, que también repasa estos acontecimientos de la infancia de Ana Ozores, la misógina sociedad del XIX considera la sexualidad femenina como algo problemático, conflictivo, criminal: "a woman is perpetually on the verge of criminality, even if she is only a child" (1987: 92). Noël Valis (1984) señala, por otra parte, la constante asociación en La Regenta de la sexualidad con imágenes escatológicas de las cuales el sapo es la suprema instancia. Pues bien, el beso final del sapo lo interpreta Valis como el símbolo de la definitiva separación de Dios, de la condena de Ana al infierno. Se insiste, por tanto, en la idea de la sexualidad femenina como criminalidad, como pecado.

\subsection{LA IGLESIA Y LA ARISTOCRACIA. DOS PODERES "FALOCENTRICOS" EN LUCHA POR... UNA MUJER}

No pocas críticas feministas han destacado la importancia de la Iglesia en $L a$ Regenta como reflejo de la gran influencia del estamento eclesiástico en la sociedad española de la época. Según Biruté Ciplijauskaité, Clarín se desvía del triángulo amoroso clásico y "opta por el rectángulo, poniendo en el primer plano no la vacilación entre el marido y el seductor, sino la lucha entre dos rivales" (Álvaro Mesía y Fermín de Pas), y de esa forma "enfrenta el poder civil y el eclesiástico (...), mostrando que en los dos casos se trata menos de la conquista de una mujer que de la dictadura de la ciudad" (1984: 56). Gascón Vera piensa que el adulterio "no es nada más que el pretexto para la exposición de las fuerzas falocéntricas del poder erótico que ejerce el hombre sobre la mujer" (1992: 156). Esas "fuerzas falocéntricas" son el poder mundano, representado por don Álvaro, y el poder espiritual, representado por don Fermín. Y Gascón Vera puntualiza: "En La Regenta estos poderes universales (...) parecen condenados y denigrados. Pero una lectura femenina podría constatar que, a pesar de la crítica del autor, éste también acepta la fuerza de estos poderes, ya que los hace triunfar a través de la realidad del rechazo y del abandono en que se verá sumida la mujer al final de la novela" (Ibid.). De nuevo la crítica feminista condena la actitud de Clarín, de nuevo se evidencia aquí el carácter realista de una parte de esta crítica, que cree ver en la obra el reflejo de la experiencia de su autor. Sara Schifter destaca también la dimensión colectiva, sociológica, que tiene el triángulo amoroso formado por Ana, Álvaro y Fermín. A Schifter le parece un juego o una cacería con dos cazadores y una víctima: Ana. Y es un juego en el que toma parte toda Vetusta, pues cada uno de los contrincantes tiene sus seguidores (el Casino y Visitación por parte de Álvaro, y la iglesia y doña Petronila por parte de Fermín). Algunos de ellos, como Visitación o la marquesa de Vegallana, ayudan a ingeniar la seducción de Ana y se alegran cuando ésta se ha consumado porque así la virtud de la Regenta ya no las deja en entredicho. Los hombres también parecen contentos. Según Gerrard, la caída final de La Regenta en brazos de su amante es vista por Vetusta como una confirmación de la debilidad de la mujer y Gerrard vuelve a insistir en la misoginia 
de una sociedad que exige castidad a las mujeres pero al mismo tiempo cree firmemente que la castidad es algo imposible en ellas (1987: 94). Ciplijauskaité llama la atención sobre el hecho de que Clarín es el único que salva a la protagonista de la muerte, que no le impone la muerte como castigo, a diferencia de Flaubert, Tolstoi y Fontane. Sin embargo, su castigo es, en opinión de Ciplijauskaité, aún más cruel: "En realidad, la pena es mayor: debe enfrentarse a la sociedad que antes la halagaba y la envidiaba, quedando totalmente sola y pobre" (1984: 65). Otra vez se pone en entredicho la actitud del escritor.

\section{LA REGENTA, FREUD Y LA CRÍTICA FEMINISTA}

En relación con esta cuestión del final de la novela, voy a detenerme en las teorías de Bridget A. Aldaraca, que traen a colación la intensa crítica hecha al psicoanálisis desde el feminismo. Aldaraca comienza señalando la relación del título de su trabajo "El caso de Ana O." con el famoso caso de Anna O. que inicia Los estudios sobre la histeria de Breuer y Freud, publicados diez años después de La Regenta. Intenta establecer de esta forma un paralelismo entre el discurso narrativo de la novela realista y naturalista y el discurso científico decimonónico basado en el positivismo que está en la base del psicoanálisis freudiano. Estos dos tipos de discurso confían plenamente en la objetividad de sus planteamientos y, en consecuencia, niegan la subjetividad del científico y del escritor. Aldaraca lo llama "la desubjetivación o la cosificación del agente del acto científico" (1990: 60). Y, sin embargo, Aldaraca evidencia el lenguaje metafórico, literario, narrativo, empleado por algunos médicos para describir los síntomas de la histeria, y al mismo tiempo compara el relato de la vida de Ana Ozores con "el estudio de un organismo en un experimento de laboratorio" (id.: 56), atendiendo especialmente al ambiente social que rodea a ese organismo y que determina su comportamiento y su conducta patológica. El fanatismo religioso, la estrecha moral social de la aristocracia en una ciudad de provincias, los condicionantes económicos que la conducen a un matrimonio sin amor con un hombre mucho mayor que ella, son factores decisivos para que Ana desarrolle la enfermedad de la histeria. La frustración de sus deseos sexuales a causa de la impotencia de su marido, don Víctor Quintanar ${ }^{8}$, es una de las razones de sus ataques histéricos, aunque Aldaraca insiste en que "Alas pone el amor en todas sus manifestaciones bajo su microscopio" (Ibid.: 57), y añade como otros posibles motivos la pérdida del amor filial durante la infancia con la muerte de los padres. Pero quizás lo más interesante sea la explicación que ofrece del episodio final de la novela, cuando Ana se desmaya y la besa furtivamente Celedonio, el acólito. Aldaraca relaciona el episodio con otro caso de histeria descrito por Freud, el de Dora. Freud tardó varios años en publicar el historial de esta mujer porque ella lo abandonó y se quedó sin el desenlace médico previsible: la curación o la muerte. Que Ana despierte de su desvanecimiento, que tenga que volver a casa y seguir viviendo contradice, según Aldaraca, el desenlace médico que para las historias de adulterio había adoptado la novela realista hasta ese momento, la muerte:

\footnotetext{
${ }^{8}$ Aldaraca es tajante al respecto: "Alas destaca la importancia de la vida sexual del matrimonio haciéndonos entender que el ex regente Víctor Quintanar es y siempre ha sido impotente" (Ibid.: 56).
} 
El historial clínico sólo tiene dos posibles desenlaces, o la curación o la muerte. Cualquiera de los dos nos permite olvidarnos de la enferma, olvidar su historia. En el mundo de la novela del XIX, Emma Bovary tranquiliza al público conservador francés, suicidándose, Ana Karenina nos resuelve el problema de su existencia dejándose aplastar por el tren. Pero Ana despierta de su pesadilla para encontrarse todavía en ella. Y no tendrá más remedio que volver a su casa y seguir viviendo (1990: 60-61).

Aldaraca parece indicar que la mujer se resiste a dejarse encasillar en los patrones médicos, psicológicos, sociales y literarios del XIX. Obsérvese cómo importa muy poco que quien plantee ese desenlace sea un hombre (Clarín), porque Aldaraca, al evidenciar la pretensión de objetividad en el psicoanalista y en el novelista decimonónico, no sólo la pone en entredicho sino que se distancia de aquellas corrientes críticas de carácter realista que analizan la obra como reflejo de su autor. La lectura de Aldaraca, instalada ya de pleno en el horizonte postestructuralista, no cree en la existencia de un significado estable en la obra literaria, del que el autor aparezca como garante, sino que apuesta por que sea el lector quien construya ese significado. Es lo que ella hace.

\section{El FEMINISMO CLÁSICO Y LOS ESTEREOTIPOS FEMENINOS: DEL "ÁNGEL CAÍDO" A LA "MADRE FÁLICA"}

En cambio, la crítica feminista que parte de presupuestos humanistas y realistas ha destacado el carácter estereotipado de Ana Ozores. Si una lectura en clave postestructuralista, dominada por el relativismo y el subjetivismo, conduce lógicamente hacia la individualización del personaje, una lectura en clave realista, asentada en el concepto de lo típico, de lo representativo, termina sin más remedio en el estereotipo. Schifter, por ejemplo, describe a Ana Ozores como "arquetipo trágico femenino" (1982: 230) y Lisa Gerrard, que la ve como símbolo de la frustración femenina en una sociedad machista, se detiene en las imágenes cosificadas que de ella ofrecen otros personajes de la novela. Su padre, por ejemplo, la contempla "como si fuese el arte", "como si no tuviera sexo". Para sus tías no es sino un objeto en el mercado matrimonial al que hay que engordar para que la ganancia sea mayor. Y la ciudad la considera por su belleza, junto con la torre de la catedral y el paseo, como una de "las tres maravillas de la población” (1987: 92). Además, el único modo de superar su insatisfacción sexual es a través de la religión llegando a convertirse, según Gerrard, en el fiel reflejo de un modelo en este caso literario: La perfecta casada de Fray Luis de León (1987: 93).

Catherine Jagoe (1988) utiliza también un arquetipo, la imagen bíblica del ángel caído, para explicar la capitulación final de la Regenta, la mutilación de Tristana y la muerte de Fortunata.

Y Lou Charnon-Deutsch (1990) observa que la representación de la mujer en la narrativa clariniana es la de un adversario: las figuras femeninas con frecuencia simbolizan los obstáculos que impiden la maduración social de los personajes masculinos y además se las define a partir de la idea de la determinación biológica.

Otro estereotipo femenino del que la crítica se ha ocupado es el de la madre fálica. Tal calificativo merece, según Gascón Vera, la madre del Magistral ya que "se comporta como un símbolo de lo masculino actuando siempre sin emotividad hacia 
el hijo y viendo en él la realización de sus ambiciones y la réplica y continuación de su vida dura e implacable donde el poder y el dinero son lo más importante" (1992: 166). De esta "madre terrible", Alison Sinclair (1999) ha destacado su ambigüedad sexual y su poder.

\section{CONTRA EL DON JUAN Y EL MARIDO BURLADO}

Y no faltan tampoco interesantes reflexiones sobre los modelos masculinos presentes en La Regenta, con especial atención a la quiebra de patrones clásicos como el don Juan o el marido burlado (Ciplijauskaité, 1984: 84-89). A nuevas relaciones familiares y sociales corresponden nuevos tipos humanos. Esta es la tesis de Ciplijauskaité, que utiliza la expresión "el don Juan desdonjuanizado" para referirse a "la demolición del don Juan tradicional" (1984: 84): Clarín presenta a un Álvaro Mesía ya algo mayor, que ha de administrar sus fuerzas, que tiene mala puntería y que es un cobarde, como demuestra su huida final. En cuanto al marido burlado, "Ninguno, salvo Karenin, odia al seductor. Es más: inconscientemente, en un punto u otro, ayudan en la tarea de seducción, introduciendo un elemento cómico o grotesco" (id.: 89). La ingenuidad, la mediocridad y la bondad son algunos rasgos de Víctor Quintanar. Clarín lo muestra con frecuencia alentando a don Álvaro para que conquiste a Ana. Su reacción, cuando conoce el adulterio, es literaria: Clarín lo llama "espadachín lírico", no tiene intención de matar a nadie (planea tirar a las piernas) y no cree que don Álvaro sea capaz de alcanzarle a tanta distancia. Pero Clarín lo hace sucumbir a la fatalidad no de un honroso y fatal disparo al corazón sino de un balazo en la vejiga.

\section{LA CRÍTICA DE LOS ESTEREOTIPOS DESDE EL MATERIALISMO CULTURAL}

La crítica feminista inspirada en el materialismo cultural ha hecho una importante objeción al feminismo humanista tradicional responsable de lecturas arquetípicas como las que acabamos de mostrar. Es la siguiente: los personajes femeninos y los masculinos son analizados como si encarnasen una esencia homogénea y ahistórica, y esto supone aceptar la eternidad de las distinciones de género y, en consecuencia, asumir la imposibilidad de acabar con las desigualdades que estas distinciones vienen alimentando desde hace siglos (Newton y Rosenfelt 1985: xvi-xvii; apud Sagarra y Carabí 2000: 43-46). Presentar a la Regenta como el emblema de la tragedia, de la frustración, de la caída de la mujer -así, en singular- conlleva en cierta forma la implícita aceptación de que es ésa justamente la esencia femenina. Sin embargo, no hay que menospreciar, en mi opinión, el valor de este tipo de crítica, propia de una fase inicial de desarrollo del feminismo y por ello interesada en hacer visible la difícil situación de las mujeres en una sociedad dominada durante mucho tiempo por valores patriarcales. Y habría que incluir además una precisión respecto al trabajo de Ciplijauskaité. Aunque su perspectiva es realista ya que presenta los nuevos paradigmas masculinos como un reflejo del cambio que se está produciendo en las relaciones familiares del XIX, se aproxima un tanto a la crítica feminista materialista al remitir esos arquetipos a imágenes no eternas sino concretas, pertenecientes a una época, históricamente bien delimitadas. 


\section{Ana Ozores, Bajtin, Derrida... Y LA CRÍticA FEMINISTA}

Por otra parte, la crítica de naturaleza semiótica, inspirada en las teorías de Bajtin sobre la ficción, y la crítica deconstructiva han producido también interesantes acercamientos a La Regenta, relacionados en la mayoría de los casos con el lugar que la literatura (San Agustín, Santa Teresa, Chateaubriand, Don Juan Tenorio, etc.) tiene en la obra.

Por ejemplo, Diane F. Urey explica la pasión de Ana Ozores por los libros como la búsqueda de la propia identidad. Por eso, Ana reescribe esos libros y los hace hablar de acuerdo con sus deseos, creándose así un "endless intertextual process" (1990: 36) ${ }^{9}$. Y por eso también, cuando Álvaro la abandona y ella sucumbe al dolor y a la enfermedad, renuncia a la lectura y a la escritura, y esa renuncia la interpreta Urey como un símbolo de su muerte (id.: 42). Además, la indagación constante de una identidad y la imposibilidad de establecerla las coloca Urey en paralelo con el proceso mismo de la narrativa ${ }^{10}$. De igual forma, la figura de Celedonio, que espía a la Regenta mientras lee y que después la besará al final de la novela, no es para Urey sino un trasunto del lector y un magnífico ejemplo de las tesis derrideanas sobre el lenguaje: el lenguaje no representa la realidad sino que la difiere, evidencia no su presencia sino su ausencia ${ }^{11}$.

Elena Gascón Vera hace una perspicaz observación sobre The Fate of Reading and Other Essays (1975) de Geoffrey Hartman, que muy bien podría aplicarse a esta figura del lector masculino (Celedonio) y al libro-mujer (Ana) que él lee: "La mayoría de los críticos asumen que el lector típico es un hombre y algunos, como Geoffrey Hartman, comparan el leer al placer que el hombre siente al mirar a las chicas en cuyo proceso, según él, uno se siente perjuro, asesino, truculento, lleno de culpa. Así pues las mujeres, que teóricamente también al leer se basan en sus propias experiencias, no pueden sentir el placer de mirar a los chicos, sino, más bien, la desazón de ser miradas, de considerarse las chicas humilladas, restringidas y marginadas por la mirada del otro" (1992: 157-158).

En definitiva, la identidad de Ana Ozores es un proceso sin fin de búsqueda presidido por una intertextualidad infinita que, salvando las distancias, ejemplifica muy bien el proceso mismo de la narrativa, y al que sólo puede poner fin el lector. De ahí que Sieburth (1987) afirme que La Regenta contiene múltiples versiones literarias de su propio argumento ${ }^{12}$. La conflictiva personalidad femenina de Ana Ozores queda

\footnotetext{
9 "As the reader looks to other texts in search for a more complete reading of La Regenta, so Ana seeks fulfillment for the loss of her mother and satisfaction of her spiritual and physical yearnings in books, both the ones she reads and the ones she writes, like the poems and novels of her youth" (Ibid.: 36-37).

10 "Ana's efforts thus reiterate and reflect the processes of character, plot and interpretation that constitue the narrative" (Ibid.: 30).

11 "This first scene, then, of Ana reading, is at a distance from the observer/reader and the "present" of the narrative, which is only another optical illusion. Ana is representating, just like the book she is reading. Her presence is a figment of Celedonio's imagination, deferred through the spy glass and throug time" (Ibid.: 32). Y continúa: "Words dissimulate the absence of reality, just as Ana's image reveals no real presence and $\mathrm{La}$ Regenta is only a book, not reality" (Ibid.: 33).

12 Por ejemplo, "The relationship between Santa Teresa and her confessor is the impetus for all possible variants of relations between the clergy and women. There are Obdulia's relations with the Bishop of Nauplia; Olvido's mystic love for Don Fermín; Fermín's relations with Teresina and Petra; his domination of Sor Teresa" (Ibid.: 281). Y todas ellas, por supuesto, como un trasunto de la relación entre Ana y don Fermín.
} 
entonces atrapada en el lenguaje, en la literatura, como ente ficcional perfectamente individualizado cuya representatividad sólo puede ser leída en términos literarios. Es más, según Sieburth, la continua oscilación entre el estereotipo literario y la singularización del personaje evidencia la energía entrópica de la obra, su naturaleza dialógica (id.: 290).

El feminismo humanista, en cambio, interpreta la pasión de la Regenta por la lectura y la escritura como una secreta vía de escape, como un refugio contra la vida sin sentido a la que es condenada por la sociedad machista (Schifter 1982: 230-236 y Gerrard 1987: 92-93). Pero la sociedad veta incluso esa salida censurando la dedicación de la mujer a la literatura. Como apunta Ciplijauskaité, "el descubrimiento de que Anita escribe poesía causa consternación en todos los sectores” (1984: 71). La Regenta aparece entonces como el símbolo de las dificultades femeninas para acceder a la escritura ${ }^{13}$. El texto de nuevo se interpreta como reflejo de la situación real de la mujer. En un caso Ana, ser fragmentario y dividido, queda aprisionada en el lenguaje, en la metaliteratura, en la metaficción; y en otro, su imagen (su esencia única, homogénea y coherente) se fija en un espejo en el que quizás es ella la única que no se reconoce.

Los prejuicios en contra de la mujer lectora son evidentes en lo que Nora Catelli (1995) llama el "bovarysmo" o la "mala lectura" que las protagonistas de las novelas del XIX hacen de los clásicos, es decir, de los "buenos libros". La lectura femenina es reputada siempre como "mala" en este período por lo que tiene de "sentimental", de "autorreferencial", de "adolescente", y por tanto, de privada, de doméstical4. $\mathrm{Y}$ en el caso concreto de Ana Ozores, sus consecuencias son funestas, puesto que, además de impulsarla a la escritura de malos versos, la abocan a un intenso desarreglo nervioso ${ }^{15}$.

\section{El psicoanálisis lacaniano en La Regenta. Santa Teresa y doña Inés, DOS OSCUROS OBJETOS DE DESEO}

Pero si hay dos lecturas que jueguen un papel fundamental en La Regenta son el Don Juan Tenorio y Santa Teresa. Las teorías psicoanalíticas sobre la psicología femenina, tanto las freudianas como las lacanianas, van a estar presentes en el sugestivo

\footnotetext{
13 "The message is clear: female creativity outside of the female capacity to create life in the womb is inappropriate and borders on scandal" (Schifter, 1982: 236).

14 "Y ¿qué quiere decir en este contexto "malo"? "Malo" sólo quiere decir sentimental, en el sentido de autorreferencial o adolescente: como producto de un mecanismo destinado a reducir todo lo abstracto al mundo cotidiano de la experiencia de los sentimientos vividos. Si se define efectivamente como mala lectura aquélla que postula como único punto de referencia la experiencia "real" y si, además, estamos hablando de la experiencia "real" de las mujeres, es lógico que sólo nos refiramos a lo privado. En las dos acepciones: por un lado, privado es doméstico; por otro, privado es carente de acuerdo entre la esfera de la acción y la esfera del pensamiento. Las mujeres lectoras, entes domésticos y carentes, convierten la gran literatura y el gran pensamiento en una extensión de su privacidad y de su privación” (1995: 127).

15 "No sólo lee, sino que escribe: la escena que culmina el recorrido por la "biblioteca" de la Regenta muestra a la joven en un estallido de patética efusión tras haber intentado hacer versos. La voz del narrador pasa de la ironía al sarcasmo y, de alguna manera, pone las cosas en su lugar. Soterradamente nos dice que Ana Ozores puede leer todo eso, pero que la consecuencia de la frecuentación de Homero y San Agustín es la escritura de versos malos y el estallido de un desarreglo de los sentidos" (1995: 126).
} 
análisis que James Mandrell (1990) realiza sobre la "malevolent" presencia del drama de Zorrilla y de la mística en La Regenta. Como Bridget A. Aldaraca, Mandrell parte de la estrecha relación entre las investigaciones psicoanalíticas y las de la novela realista y naturalista del XIX ${ }^{16}$. Según Freud, la mujer, inferior por naturaleza al hombre, posee un menor sentido de la justicia, es incapaz de sublimar sus instintos y sus intereses sociales son exiguos. En ella el complejo de Edipo se resuelve en el ansia de posesión del poder masculino y patriarcal. Por eso, como apunta Lacan, es una ausencia que no puede convertirse en presencia. Para Lacan, los hombres y las mujeres existen únicamente en el lenguaje, y las mujeres, como ausencia, sólo son objeto de las fantasías masculinas. Mandrell, que ve en Álvaro y en Fermín "two avatars of Don Juan" (1990: 19), utiliza estas teorías para explicar la función del texto donjuanesco en la novela: "The absence that is woman is filled with the presence that is man and patriarchal desire at the same time that Ana's "wants" are supposedly fulfilled by Fermín de Pas and Álvaro Mesía, which is to say, La Regenta is filled with Don Juan Tenorio" (id.: 8). Ahora bien, puesto que la mujer es ausencia, el placer femenino lo coloca Lacan más allá del falo y lo relaciona con la mística ${ }^{17}$. El deseo místico, "this non-phallic jouissance" se caracterizaría por "the combination of sexual experience with the lack of sexual knowledge" (ibíd.: 7), y estaría presente en La Regenta gracias a la figura de Santa Teresa. Don Juan y Santa Teresa constituyen así "the two extremes of desire" en la novela, llegando incluso a entrar en conflicto. No en vano el Magistral teme que la lectura de Santa Teresa lo aparte de Ana. Pero Mandrell ve en este otro tipo de deseo una variante más del masculino, tanto por la relación amorosa que el Magistral tiene con Sor Teresa como porque Ana acaba cayendo si no en los brazos de Fermín, en los de Álvaro, y abandonando sus lecturas místicas. Santa Teresa se convierte entonces en un reflejo de Doña Inés, la novicia que muere y salva al seductor ${ }^{18}$. Y, por ello, mientras la novela finaliza con la muerte social de Ana, Álvaro y Fermín pueden continuar con sus vidas y sus conquistas. En este sentido a Mandrell le parece que Clarín es "less sympathetic manner than Lacan" (id: 23), aunque la conclusión del psicoanálisis y de Clarín sea, en su opinión, la misma: "To be sure, the marginality of the protagonist and eponymous heroine of the novel as it is effected by the narrator and author of La Regenta corresponds to the marginalizing and patriarchal tendencies of the psychoanalytic theories of Freud and Lacan..." (ibíd.: 23-24). Esta lectura psicoanalítica, que concluye abjurando del psicoanálisis, evidencia por un lado las siempre controvertidas relaciones del psicoanálisis con el feminismo, y por otro la importancia que para la crítica psicoanalítica tiene el autor. No en vano Mandrell termina por hacer responsable a Clarín de la transmutación del

\footnotetext{
16 "What are Anna Karenina, Madame Bovary, and La Regenta, to give only three examples, if not considerations of and answers to the question, "What does woman want?" In the other words, the subject that Freud was to explore in the "scientific" terms of psychoanalysis, novelist in the realist tradition were exploring in the language of fiction" (Ibid:: 5).

17 "The quintaessential expression of the unknowable pleasure that is associated whit the woman is to be found in mystic desire as it is experienced by woman and men, since "there are men who are just as good as women" " (apud Mandrell, ibíd.: 7).

18 "There is, therefore, in the world of La Regenta, no femenine model of desire that stands apart from the masculine other. Everything is contingent on masculine models of desire whereby the feminine exists only as a projection of the desires of men. In this context, Santa Teresa inevitably becames like Don Juan's Doña Inés, the text of seduction and salvation" (Ibid.: 23).
} 
deseo femenino en una variante más del masculino, convirtiéndolo en el principal aval de la verdad del texto, una verdad que, aunque leída en términos metaliterarios (no perdamos de vista que el objetivo primordial es dilucidar el papel de Don Juan Tenorio en la novela), no deja de ser única y acaba por aparecer como representativa del sometimiento de la mujer a los poderes patriarcales, y entre ellos, al psicoanálisis, tanto el freudiano como el lacaniano. Por esta razón, el análisis de Mandrell no está tan lejos de la crítica feminista humanista. De hecho, desde esa crítica se han señalado también modelos femeninos religiosos que escapan a la autoridad masculina. Según Sara E. Schifter, Ana Ozores aprende a superar su insatisfacción sexual mediante el éxtasis místico, desarrollando al mismo tiempo una gran devoción por la Virgen, a la que dedica poemas y plegarias. Pues bien, para Schifter, la Virgen representa la imagen de una mujer separada del dominio masculino, imagen que proporciona la posibilidad de una identidad femenina libre de las normas patriarcales y lejos por fin del tópico de la fémina diabólica ${ }^{19}$.

En definitiva, desde la sociología literaria al materialismo cultural, pasando por el psicoanálisis, la semiótica o la deconstrucción, el feminismo ha recorrido un largo y apasionante camino, y La Regenta lo ha recorrido con él.

\section{OBRAS CITADAS}

Aldaraca, Bridget A. 1990. "El caso de Ana O.: histeria y sexualidad en La Regenta". Asclepio 42: 51-61. 1992. El ángel del hogar: Galdós y la ideología de la domesticidad en España. Madrid: Visor.

Andreu, Alicia. 1996. "La crítica feminista y las obras de Benito Pérez Galdós y Leopoldo Alas". Breve historia feminista de la literatura española (en lengua castellana). Coord. Iris M. Zavala. Barcelona: Anthropos. III. 31-48.

Aragay, Mireia. 2000. "Feminismo y materialismo cultural: ¿enemigos o cómplices". Feminismo y crítica literaria. Eds. Marta Segarra y Àngels Carabí. Barcelona: Icaria. 43-69.

Catelli, Nora. (1995). "Buenos libros, malas lectoras: la enfermedad moral de las mujeres en las novelas del siglo XIX". Lectora. Revista de Dones i Textualitat 1: 121-133.

Ciplijauskaité, Biruté. 1984. La mujer insatisfecha. El adulterio en la novela realista. Barcelona: Edhasa.

.2004. "El adulterio desde La Regenta hasta la novela de hoy". II Congreso Internacional de Literatura Comparada, Universidad de Vigo, 5-7 de noviembre de 2002. La construcción del yo femenino en la literatura. Cádiz: Servicio de Publicaciones de la Universidad de Cádiz. 243-261.

Charnon-Deutsch, Lou. 1990. Gender and Representation. Women in Spanish Realist Fiction. Amsterdam / Filadelfia: John Benjamins Publishing Co.

Durand, Frank. 1990. "Structure and the drama of role-playing in La Regenta" Malevolent Insemination and Other Essays on Clarín, Ed. Nöel Valis. Ann Arbor, Michigan: University of Michigan. 141-154.

\footnotetext{
19 "The Mary symbol has given Catholic women (as opposed to Protestant women who have denied Mary's divinity) the possibility of a spiritual identity independent of patriarchal rule. The sanctification of the Virgin thus mitigates the power of the myth of femenine evil and frees woman of the need to be saved by the male" (1982: 233).
} 
García, Carlos Javier. (2002). "Un final sexuado de La Regenta”. Las representaciones de la mujer en la cultura hispánica. Eds. K. M. Sibbald y Ricardo de la Fuente Ballesteros. Valladolid: Universitas Castellae. 151-160.

Gascón Vera, Elena. 1992. Un mito nuevo: la mujer como sujeto-objeto literario. Madrid: Pliegos.

Gerrard, Lisa. 1987. "The Feminist Dimension in La Regenta". Letras femeninas XIII.1-2: 91-99.

Gullón, Germán. 2002. "La pasión al natural en La Regenta: Ana Ozores y su doncella Petra”. Congreso Internacional Leopoldo Alas Clarín en su centenario (1901-2001): espejo de una época. Eds. Pilar García Pinacho e Isabel Pérez Cuencia. Madrid: Universidad San Pablo-CEU. 223-238.

Jagoe, Catherine. 1988. Ambiguous Angels: Gender in the Novels of Galdós. Northen Illinois University.

Labanyi, Jo. 1991. "Mysticism and Hysteria in La Regenta. The Problem of Female Identity". Feminist Readings on Spanish and Latin-American Literature. Eds. Linda Condé y S. M. Hart. Nueva York: Mellen Press. 37-46.

Lyssorgues, Yvan. 1989. Clarín político. Prólogo de Gonzalo Sobejano. Barcelona: Lumen.

Mandrell, James. 1990. "Malevolent Insemination: Don Juan Tenorio in La Regenta". Malevolent Insemination and Other Essays on Clarín. Ed. Nöel Valis. Ann Arbor, Michigan: University of Michigan. 1-28.

Moi, Toril. 1987. Teoría literaria feminista. Madrid: Cátedra, 1988.

Navas Ocaña, María Isabel. 2007. Historia de la teoría y la crítica literaria en Gran Bretaña y Estados Unidos. Madrid: Verbum.

Newton, Judith y Rosenfelt, Deborah eds. 1985. Feminist Criticism and Social Change: Sex, Class and Race in Literature and Culture. Nueva York y Londres: Methuen.

Ortiz Aponte, Sally. 1971. Las mujeres de "Clarín”: esperpentos y camafeos. San Juan de Puerto Rico: Universidad de Puerto Rico.

Rodrigo Mancho, Ricardo. 2002. "Del arte de la obstetricia de Feijoo a la transformación del pudor en Su único hijo (1890), de Clarín”. Perversas y divinas. La representación de la mujer en las literaturas hispánicas: El fin de siglo y/o el fin de milenio actual. Eds. Carme Riera, Meri Torras e Isabel Clúa. Valencia: Ediciones e Cultura. II. 327-333.

Rossell, Anna. 1997. "La construcción del vacío femenino en Effi Briest y La Regenta". Lectora. Revista de Dones $i$ Textualitat. Dossier "La representació de les dones a les literatures hispàniques finiseculars. Coord. Carme Riera. 3: 125-133.

Saavedra, Luis. 1987. "El escritor y su ideología. Interpretación de los personajes femeninos en la obra de Clarín”. Literatura y Vida cotidiana. Actas de las Cuartas Jornadas de Investigación Interdisciplinaria. Eds. Ma Ángeles Durán y José Antonio Rey. Madrid / Zaragoza: Seminario de Estudios de la Mujer de la Universidad Autónoma de Madrid y Universidad de Zaragoza. 261-275.

Sánchez, Elizabeth D. 1990. "Beyond the realist paradigm: subversive strategems in La Regenta and Madame Bovary”. Malevolent Insemination and Other Essays on Clarín, Ed. Nöel Valis. Ann Arbor, Michigan: University of Michigan. 101-116.

Sánchez-Eppleer, Benigno. 1987. "Stakes: the sexual vulnerability of the reader in La Regenta". Romanic Review, LXXVIII, 2, New York, Columbia University Press. 202-217.

Schifter, Sara E. 1982. "La loca, la tonta, la literata: Women's Destiny in Clarín's La Regenta”. Theory and Practice Feminist Literary Criticism. Eds. Gabriela Mora y Karen S. Van Hoof. Ypsilanti, Michigan: Biligual Press / Editorial Bilingüe. 229-241.

Semprúm Donahue, Moraima de. 1973. "La doble seducción de La Regenta". Archivum 23: 11-33.

Sieburth, Stephanie. 1987. "Interpreting La Regenta: Coherence vs Entropy”. Modern Language Notes 102. 2: 275-291.

.1990. "Kiss and tell: the toad in La Regenta. Malevolent Insemination and Other Essays on Clarín, Ed. Nöel Valis. Ann Arbor, Michigan: University of Michigan. 87-100. 
Sinclair, Alison. 1995. "The force of parental presence in La Regenta". Culture and Gender in Nineteenth-century Spain. Eds. Lou Charnon-Deutsch y Jo Labanyi. Oxford: Oxford Clarendon Press. 182-199.

Six, Abigail Lee. 1995. "Mother's voices and Medusas' eyes: Clarín's construction of gender in Su único hijo". Culture and Gender in Nineteenth-century Spain. Eds. Lou CharnonDeutsch y Jo Labanyi. Oxford: Oxford Clarendon Press. 199-216.

Socías, Margalida. 2002. ““'Otras” heroínas de la narrativa del XIX. La mujer en los cuentos de Clarín". Congreso Internacional Leopoldo Alas Clarín en su centenario (1901-2001): espejo de una época. Eds. Pilar García Pinacho e Isabel Pérez Cuencia. Madrid: Universidad San Pablo-CEU. 175-186.

Suárez Lafuente, María Socorro. 1988. "A presupposition of Intertextuality in Clarín's $L a$ Regenta and Chopin's The Awakening". Romanic Review LXXIX. 3: 492-501. En New Women of Spain. Ed. Elisabeth Sotelo. Münster: Lit Verlag Münster. 2005.

Urey, Diane F. 1990. "Writing Ana in Clarín's La Regenta". Malevolent Insemination and Other Essays on Clarín. Ed. Nöel Valis. Ann Arbor, Michigan: University of Michigan. 29-45.

Valis, Nöel Maureen. 1981. The Decadent Vision in Leopoldo Alas. Baton Rouge, Louisiana: Louisiana State University Press.

1984. "Sobre la última frase de La Regenta". Clarín y La Regenta en su tiempo. Actas del simposio internacional. Oviedo: Universidad de Oviedo. 795-808. 